\title{
Tests of thermal resistance of simulated walls with the reflective insulation
}

\author{
Jerzy Zb. Piotrowski ${ }^{1}$, Łukasz J. Orman ${ }^{1, a}$, Xavier Lucas ${ }^{2}$, Ewa Zender-Świercz ${ }^{1}$, Marek Telejko ${ }^{1}$ and Dorota Koruba ${ }^{1}$ \\ ${ }^{1}$ Kielce University of Technology, 25-314 Kielce, Poland \\ ${ }^{2}$ REBOND sp.z o.o., 25-663 Kielce, Poland
}

\begin{abstract}
The paper presents the thermal resistance characteristics of walls with multilayer reflective insulation. The tests have been performed using a heat flow meter to determine the resistivity of the layers simulating partition walls in buildings. A modification of the structure has also been proposed and analysed with a view to increase the thermal resistance and, consequently, reduce the heat flux transferred through the walls. Consequently, walls produced with layers that ensure higher thermal insulation lead to better thermal performance properties of the whole buildings, which reduce heating/cooling costs throughout the year.
\end{abstract}

\section{Introduction}

Buildings consume significant amounts of energy. In the winter heat losses occur to the outside while in the summer heat gains from the surroundings lead to overheating problems or - in the case of buildings equipped with air conditioning systems - to more power consumed for cooling purposes. Consequently, proper thermal insulation of buildings is necessary in order to ensure low energy demand as well as thermal comfort for people. Moreover, energy saving initiatives are related to environmental protection because of smaller amounts of gaseous and particulate air pollution emitted from power production installations - both home boilers and large power stations.

Traditional methods of thermal insulation of buildings are well known and have been used for decades. Nowadays, in many applications the reflective insulation can be considered as a replacement of traditional materials such as foams or fibreglass. Some scientific effort to clarify the physical processes that occur inside building elements with such material has been made so far, but much remains to be determined. It is quite crucial become more widespread use of this type of insulation might be anticipated. Consequently, knowledge about the physical phenomena occurring in this type of materials should be more recognized.

Reflective insulation consists of low - emittance surfaces (usually reflective foils) that radiate the heat back to a warmer element, thus, protecting the surface from accepting radiant heat, and enclosed air spaces such as bubble foils or expanded polystyrene which provide additional protection from heat losses. Traditional insulation limits the conduction heat transfer by trapping air, while the additional benefit of using the reflective insulation is the ability to reduce the radiation heat transfer. Nevertheless, this type of insulation has its drawbacks. One of them is the natural convection that occurs in the air gaps. This phenomenon might have a significant impact in the case of considerably wide gaps of air.

Most works on the reflective insulation performance in literature focus on using this type of insulation in the summer period to protect against significant heat loads e.g. [2]. Guo et al. [3] discussed the use of heat reflective insulation coating on the external east, south and west walls. The covering resulted in reducing the wall temperature by ca. $8-10^{\circ} \mathrm{C}$. Consequently, the air conditioning saving of electricity was about 5,8 $\mathrm{kWh} /\left(\mathrm{m}^{2}\right.$ month). Some works, for example [4], present the measurements of the reflective insulation performance in both winter and summer as the construction element of the walls and the roof are presented. Basing on the tests it has been stated in this paper that the application of such a material might avert the unfavourable overheating in the summer and retain heat in the winter. In [5] the evaluation of the manufacturers data of a commercial reflective insulation was presented and good agreement was found. The tests were performed using a procedure based on the test in the hot box apparatus. The same measurement technique is used in the present study.

However, laboratory measurements conducted in the small scale might not be enough to properly understand the heat transfer phenomena taking place in building elements that containe reflective insulation. This is the reason why large scale experiments have also been

\footnotetext{
a Corresponding author: orman@tu.kielce.pl
} 
introduced and their preliminary test results are presented in this paper.

It is worth noting that although calculation methods are available in literature, they might not provide very accurate results of this type of elements. As has been concluded in [6], where four methods that can estimate thermal resistance values of enclosed reflective air spaces, the obtained results generally agreed to within $10 \%$ as well as $4 \%$ if the ISO 6946 standard was not included.

\section{Samples and testing method}

The tests have been conducted on $30 \mathrm{~cm} \times 30 \mathrm{~cm}$ samples composed of two outside gypsum boards with the reflective insulation placed inside. The reflective part of the multilayer insulation is the metalized foil placed on both sides of the insulating product, other layers are inside - including air trapping foams. The total thickness of this insulation is $3 \mathrm{~cm}$. The thickness of the air gap on each side is changed from $1 \mathrm{~cm}$ to $4 \mathrm{~cm}$ with steps every $1 \mathrm{~cm}$. For the case of a $4 \mathrm{~cm}$ gap, an additional reflective, metalized foil layer has been introduced in the middle of each gap. Figure 1 shows the schematic of the analysed samples.

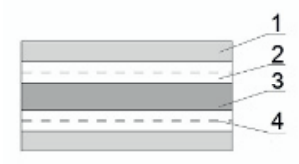

Figure 1. Sample layers: 1 - gypsum board, 2 - air gap, 3 multilayer reflective insulation product, 4 - additional reflective foil (only for a $4 \mathrm{~cm}$ air gap).

The measurements have been carried out in the so called "hot box" apparatus connected to a computer with appropriate data acquisition and visualisation software. The main components of the device are the horizontal heating and cooling plates located in the thermally isolated chamber. The heat flux is determined with sensors in the measurement area of the dimensions $10 \mathrm{~cm} \times 10 \mathrm{~cm}$ on both plates. The upper plate is movable and samples of height from $2 \mathrm{~cm}$ to $11 \mathrm{~cm}$ can be analysed. Basing on the temperature difference and the heat flux recorded during the test, the device calculates the resistivity of the considered sample. For a given height of the sample the thermal conductivity can also calculated by the software. The equipment conducts steady - state heat transfer measurements, so the temperature of each plate needs to be constant (as presented below in Figure 2) and the heat flux should also approach a certain unchangeable value, which has been shown in Figure 3.

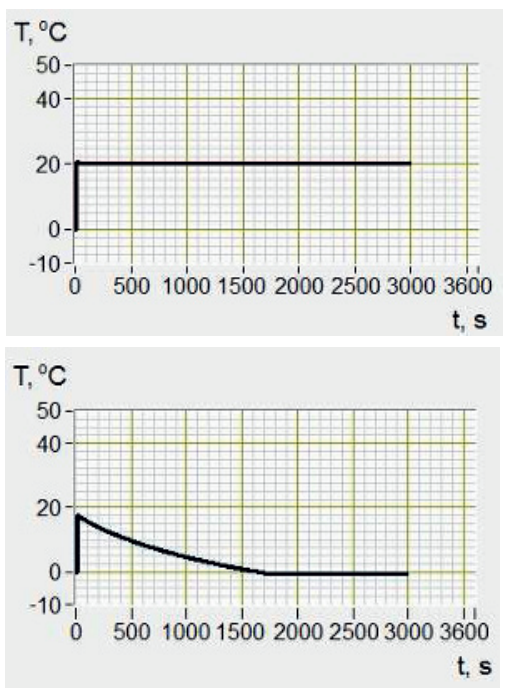

Figure 2. Temperature changes of the upper (heating) and lower (cooling) plates for sample with $2 \mathrm{~cm}$ air gap.

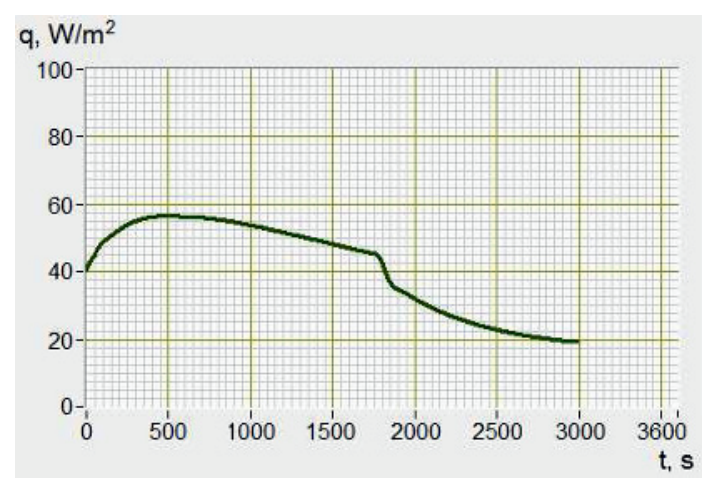

Figure 3. Changes of heat flux in time for sample with $2 \mathrm{~cm}$ air gap.

\section{Results and discussion}

The tests of the thermal resistance have been performed in the downward heat flux direction on the samples with an air gap of 1,2, 3 and $4 \mathrm{~cm}$ on each side of the simulated building element. The height of the gypsum board is $1 \mathrm{~cm}$. In order to determine if the additional reflective layer could produce a structure of better thermal insulation, two extra metalized foil layers were introduced in the middle of each $4 \mathrm{~cm}$ air gap. Such a modification could lead to a reduction in radiation and convective heat transfer. Table 1 presents the test results.

Table 1. Thermal resistance of the analysed samples.

\begin{tabular}{|c|c|c|c|}
\hline No & $\begin{array}{c}\text { Air gap } \\
\mathbf{x}[\mathbf{c m}]\end{array}$ & $\begin{array}{c}\text { Thermal resistance } \\
\mathbf{R}[\mathbf{m} \mathbf{K} / \mathbf{W}]\end{array}$ & $\begin{array}{c}\text { Additional } \\
\text { reflective layers }\end{array}$ \\
\hline 1 & 1 & 0,91 & - \\
\hline 2 & 2 & 1,10 & - \\
\hline 3 & 3 & 1,25 & - \\
\hline 4 & 4 & 1,48 & - \\
\hline 5 & 4 & 1,83 & + \\
\hline
\end{tabular}


The tests indicate that the thermal resistance increases with the increasing air gap. This dependency is linear as presented below in Figure 4.

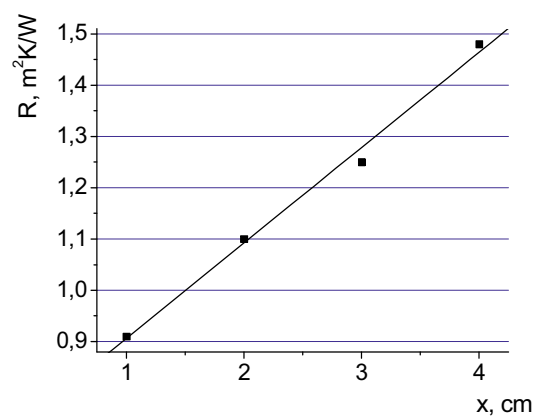

Figure 4. Dependency of thermal resistance as a function of the air gap width.

Consequently, thermal performance of the partition walls considered in this study is better as the air gap becomes larger. The presented findings are in agreement with the literature data, e.g. [6], regarding the impact of the air void width in the reflective insulation walls. Data presented in [6] for the downward heat flux indicates an almost linear dependency for small air gaps (up to ca. 3 $\mathrm{cm}$ ) present between the reflective elements. For higher values the curve becomes non-linear with values of $\mathrm{R}$ approaching a certain maximal value. At the air gap of more than $12 \mathrm{~cm}$ no significant increase in resistance with the rising void width can be observed. In the analysis of the thermal phenomena in such reflective coatings, conductivity and radiation need to be considered as well as natural convection heat transfer in the air gaps.

Generally, analysis of heat transfer is based on the following equation for thermal resistance $[6,7]$ :

$$
R=\frac{1}{E \cdot h_{r}+h_{c}}
$$

where $\mathrm{E}$ depends on the bounding thermal emittances $\left(\varepsilon_{1}\right.$ and $\left.\varepsilon_{2}\right)$ :

$$
E=\frac{1}{\frac{1}{\varepsilon_{1}}+\frac{1}{\varepsilon_{2}}-1}
$$

While $h_{r}$ is the radiation term containing $t_{m}$ - the average absolute temperature of an air gap:

$$
h_{r}=4 \cdot\left(5,67 \times 10^{-8} T_{m}^{3}\right)
$$

and $h_{c}$ describes convective heat transfer:

$$
h_{c}=\frac{N u \cdot \lambda}{d}
$$

where $\mathrm{Nu}$ is the Nusselt number calculated as a function of the Grashof number using equations obtained by the experimental results conducted in a hot box device, $\lambda$ denotes thermal conductivity of air and $d-$ width of the air gap.
It needs to be noted that the application of the additional reflective layers of thin metalized foil has resulted in an elevated overall resistivity of the considered element. The increase is quite significant in comparison to the case without the coating in the $4 \mathrm{~cm}$ gap and can be explained by both the additional resistance to the radiation heat transfer and the restricted movement of air within the whole wall. Such a modification in the composition of walls or roofs could lead to better insulation properties and, thus, reduce heating/cooling costs in buildings with such kind of insulation.

However, discrepancies might exist if the experimental results from the laboratory are turned into the practical applications in real buildings, especially that coonstruction practice makes $4 \mathrm{~cm}$ air-gap too thick, therefore - impractical. Mostly applied distant gap is 2 $\mathrm{cm}$. Consequently, a new approach might be welcome to enable more detailed modeling of heat transfer phenomena occurring in the building elements with the reflective insulation.

\section{Large-scale experimental approach}

Small - scale research data are useful, however, building materials are used in many different applications usually in large buildings, where they are subject to different conditions (variable temperatures, humidity, solar exposure, wind and other). Consequently, knowledge of the thermal performance of building materials, especially the insulation products, is crucial for the proper design of buildings and their correct maintenance.

The experiments have been designed to deal with samples placed in the climatic chamber. The chamber on the left side provide indoor air conditions, while the right side one - outside environment and contains fans (to simulate wind), lamps and water jets for rainfall simulation. Such an arrangement enables to gather complete information on the performance of building elements and their materials under different conditions. Such chambers are more and more common and tests are conducted on different materials, as in [8].

Preliminary test in the presented work have been performed on the structure insulated with the reflective insulation. The aim of the measurements was to determine the characteristic features of heat transfer on elements containing reflective insulation. The outside temperature have been set at three different values, namely: $-20^{\circ} \mathrm{C},-10^{\circ} \mathrm{C}$ and $0^{\circ} \mathrm{C}$ while the internal one at $20^{\circ} \mathrm{C}$. Heat flux transferred through the element was measured at two locations with heat flux meters. Additionally, temperature measurements have been performed with thermocouples located on the inside surface of the analysed building element. The measurements were made after steady - state conditions occurred (after temperature changes every 10 degrees Celsius). Table 2 presents the results of the investigations. The temperatures of the inner surface are taken as the mean values of the recorded temperature from each thermocouple. 
Table 2. Heat flux and temperature for the analysed samples.

\begin{tabular}{|c|c|c|c|}
\hline No & $\begin{array}{c}\text { Outside } \\
\text { temperature } \\
{\left[{ }^{\circ} \mathrm{C}\right]}\end{array}$ & $\begin{array}{c}\text { Temperature on } \\
\text { the inner surface } \\
{\left[{ }^{\circ} \mathrm{C}\right]}\end{array}$ & $\begin{array}{c}\text { Mean heat } \\
\text { flux value } \\
{\left[\mathbf{W} / \mathbf{m}^{2}\right]}\end{array}$ \\
\hline 1 & -20 & 18,53 & 31,2 \\
\hline 2 & -10 & 18,90 & 21,2 \\
\hline 3 & 0 & 18,93 & 16,2 \\
\hline
\end{tabular}

The results of the experiment have been visualised in Figure 5 for clarification.

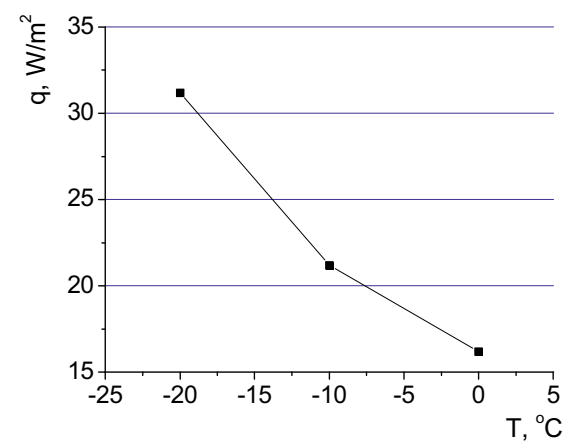

Figure 5. Heat flux test results of the element with reflective insulation for different values of outside temperature.

The obtained results indicate that the decrease in heat flux transferred through the analysed element with rising outside temperature is strongly not linear. At higher temperatures the fall rate is lower which might mean that in the region of larger temperature values the performance of reflective insulation is better. It could stem from the fact that radiation heat transfer is more dominant as temperature rises (as expressed in the Stephan - Bolzmann law, in which radiated energy is proportional to the fourth power of thermodynamic temperature of the surface). As a result, such insulation products could be quite efficient in moderate temperatures as well as high temperature in the summer, which has not been investigated in this paper. In such a case the radiation element of the heat flux could be considerable and could properly prevent the inside of the attic from overheating during the summer months when the temperature on the surface can easily reach several dozen degrees Celsius.

\section{Conclusions}

Basing on the presented test results, it can be concluded that in the investigated range of air gap values $(1-4 \mathrm{~cm})$, the thermal resistance increases linearly. However, the best performance has been provided by the application of the additional reflective layers in the middle of $4 \mathrm{~cm}$ air gap.

The analysis of the heat transfer processes in walls with reflective insulation is largely experimental and modelling requires experimental data - as in equation (4). However, with enough data (especially in the large scale experiments, which are especially vital for practical applications in building industry) it might be possible to propose a model that could help understand the phenomena and enable to design even more efficient insulation materials.

Additional experimental apparatus is planned to be used for the tests, for example infrared cameras as in the works by the author - for example $[9,10,11]$.

The reflective insulation is a fairly new concept of thermal insulation of buildings and it should become more popular, as some of its properties are more superior than the traditional insulation. As a result, research projects are underway to look for more efficient solutions.

The preliminary tests in the large scale will be continued and expended to provide more detailed data for modelling of the heat transfer processes in walls with reflective insulation.

\section{References}

1. M. J. Tenpierik, E. Hasselaar, Energy and Buildings 56, 233 (2013)

2. M. D'Orazio M., C. Di Perna C., E. Di Giuseppe, M. Morodo, J. of Building Physics, 36 (3), 229 (2013)

3. W. Guo, X. Qiao, Y. Huang, M. Fang, X. Han, Energy and building 50, 196 (2012)

4. M. G. Vrachopoulos, M. K. Koukou, D. G. Stavlas, V. N. Stamatopoulos, A. F. Gonidis, E. D. Kravvaritis, Central European J. of Engineering 2 (1), 83 (2012)

5. C. Craven, R. Garber-Slaght, Tech. report no TR 2011-01, Cold Climate Housing Research Center (2011)

6. J. M. Fricker, D. Yarbrough, Proc. of Building Simulation 2011: 12th Conf of International Building Performance Simulation Assoc., 1989, (2011)

7. D. W. Yarbrough, Materials for energy efficiency and thermal comfort in buildings, Chapter 12 (Ed. M. R. Hall, Woodhead Publishing Limited, Cambridge, 2010)

8. M. Malcho, J. Jandačka, H. Smatanová, A. Kapjor, Š. Papučík, Proc. of XV. Int. Conf. "Aplikácia experimentálnych a numerických metód v mechanike tekutin", 311 (2006)

9. Ł.J. Orman, Instal, 4A, 19 (2009)

10. Ł.J. Orman, Informatyka Automatyka Pomiary w Gospodarce i Ochronie Środowiska 3, 3 (2011)

11. Orman Ł.J., Sułek M., Conf. Terotechniologia 2009, Sc. Papers of KUT, 325 (2009) 